\title{
Comunicação terapêutica: desafios para o diálogo em uma organização hospitalar brasileira
}

\author{
Therapeutic communication: challenges for dialogue in a Brazilian \\ children's hospital
}

\section{Comunicación terapéutica: desafíos para el diálogo en uno de los hospitales pediátricos brasileños}

\author{
Luíza Mônica Assis Silva ${ }^{1, a}$ \\ luizamonica@uol.com.br | https://orcid.org/oooo-0001-9375-6736 \\ Vânia Mara Vasques Balbino de Souza ${ }^{1, b}$ \\ vmvbsouza@gmail.com | https://orcid.org/ooo0-0002-6820-5577
}

\author{
${ }^{1}$ Universidade Católica de Brasília. Brasília, DF, Brasil. \\ a Doutorado em Psicologia Social, do Trabalho e das Organizações pela Universidade de Brasília. \\ b Mestrado em Comunicação pela Universidade Católica de Brasília.
}

\section{Resumo}

Este artigo fundamenta-se nos princípios da comunicação terapêutica, do psiquiatra Jürgen Ruesch, aliados aos processos da comunicação organizacional, com vistas ao estudo e à implementação de uma comunicação específica para as organizações de saúde. A pesquisa, de caráter qualitativo, foi realizada na unidade de Onco-Hematologia Pediátrica de um hospital infantil público terciário do Distrito Federal, entre 25 de setembro e 6 de novembro de 2015, por meio de entrevistas em profundidade, aplicadas em dois grupos - profissionais da saúde e mães das crianças hospitalizadas - com o objetivo de verificar que pressupostos da comunicação terapêutica eram aplicados no tratamento das crianças e por quais categorias profissionais. Foram observados comportamentos comunicacionais conscientes, com potencial terapêutico, indicando a possibilidade de estabelecimento de um modelo comunicacional que atenda às especificidades das organizações de saúde.

Palavras-chave: Comunicação terapêutica; Comunicação organizacional integrada; Hospital; Comunicação e saúde; Jürgen Ruesch.

\begin{abstract}
This article is based on the principles of therapeutic communication, by the psychiatrist Jürgen Ruesch, allied to the processes of organizational communication, with a view to studying and to implementing a specific communication for health organizations. A qualitative research was carried out at the Pediatric Onco-Hematology unit of a public tertiary children's hospital in the Federal District, Brazil, between September 25 and November 6, 2015, through in-depth interviews, applied to two groups - health professionals and mothers of hospitalized children -, whose objective was to verify what assumptions of the
\end{abstract}


therapeutic communication were used in the treatment of the children and by which professional categories. Conscious communicational behaviours with therapeutic potential were observed, indicating the possibility of establishing a communication model satisfying the specificities of the health organizations.

Keywords: Therapeutic communication; Integrated organizational communication; Hospital; Health and communication; Jürgen Ruesch.

\title{
Resumen
}

Este artículo se fundamenta en los principios de la comunicación terapéutica, del psiquiatra Jürgen Ruesch, en los procesos de comunicación organizacional, con miras al estudio y a la implementación de una comunicación específica para las organizaciones de salud. La investigación, de natulareza cualitativa, fue realizada en la unidad de Onco-Hematología Pediátrica de uno hospital infantil público en el Distrito Federal, entre 25 de septiembre y 06 de noviembre de 2015, por medio de entrevistas en profundidad, aplicadas a dos grupos - profesionales de salud y madres de los niños hospitalizados - con el objetivo de verificar qué presupuestos de la comunicación terapéutica eran aplicados al tratamiento de los niños y por cuáles categorías profesionales. Se han observado comportamientos comunicacionales conscientes, con potencial terapéutico, que indican la posibilidad de crear un modelo de comunicación que satisfaga las especificidades de las organizaciones de salud.

Palabras clave: Comunicación terapéutica; Comunicación organizacional integrada; Hospital; Comunicación y salud; Jürgen Ruesch.

\footnotetext{
Contribuição dos autores:

Concepção e desenho do estudo: Vânia Mara Vasques Balbino de Souza e Luíza Mônica de Assis Silva.

Aquisição e análise dos dados: Vânia Mara Vasques Balbino de Souza.

Redação do manuscrito: Vânia Mara Vasques Balbino de Souza e Luíza Mônica Assis da Silva.

Revisão crítica do conteúdo intelectual: Luíza Mônica de Assis Silva e Vânia Mara Vasques Balbino de Souza.
}

Declaração de conflito de interesses: Este trabalho não apresenta conflito de interesses.

Fontes de financiamento: Capes - Coordenação de Aperfeiçoamento de Pessoal de Nível Superior.

Considerações éticas

Seguiram-se os preceitos éticos da Resolução nº 196/1996 do Conselho Nacional de Saúde, sendo aprovada pelo Comitê de Ética em Pesquisa da Fundação de Ensino e Pesquisa em Ciências da Saúde - Secretaria de Estado de Saúde do Distrito Federal FEPECS/SES-DF, por meio do parecer consubstanciado nº 1.167.793 e CAAE nº 46857715.5.0000.5553.

\section{Agradecimento/Contribuições adicionais: Capes - Coordenação de Aperfeiçoamento de Pessoal de Nível Superior, pelo} financiamento.

Histórico do artigo: Submetido: 04.set.2017 | Aceito: 04.abr.2018 | Publicado: 29.jun.2018.

\begin{abstract}
Apresentação anterior: Artigo baseado na dissertação "O cenário comunicacional do Hospital da Criança de Brasília sob a perspectiva da Comunicação Terapêutica", apresentada por Vânia Mara Vasques Balbino de Souza ao Programa de Pós-Graduação em Comunicação da Universidade Católica de Brasília, em 15 de março de 2016.
\end{abstract}

Licença CC BY-NC atribuição não comercial. Com essa licença é permitido acessar, baixar (download), copiar, imprimir, compartilhar, reutilizar e distribuir os artigos, desde que para uso não comercial e com a citação da fonte, conferindo os devidos créditos de autoria e menção à Reciis. Nesses casos, nenhuma permissão é necessária por parte dos autores ou dos editores. 


\section{Introdução}

Buscamos em Jürgen Ruesch ${ }^{1}$, professor de psiquiatria da Escola de Medicina da Universidade da Califórnia (EUA), o qual desenvolveu a comunicação terapêutica nos anos 1950, um entendimento a partir das 11 atitudes por ele chamadas de terapêuticas, considerando, primeiramente, que "a comunicação é uma função universal do homem, não está restrita em particular a nenhum lugar, tempo ou contexto; e, de um ponto de vista básico, a comunicação capaz de produzir um efeito terapêutico não difere, de modo algum, do que ocorre nas trocas comuns e ordinárias [...], não se limitando ao terapeuta e a seu paciente. Uma criança pode ser terapeuta de sua mãe e um patrão pode sê-lo de seu empregado"”.

Assim, conduz uma dinâmica para que a comunicação possa adquirir uma dimensão mais cuidadosa de tratamento, naquilo que o autor define como "atitudes terapêuticas":

Quadro 1 - Atitudes terapêuticas e suas implicações

\begin{tabular}{|c|c|}
\hline Atitude terapêutica & Comportamento \\
\hline Tolerância discriminada & $\begin{array}{l}\text { Respeito à individualidade, ausência de preconceito, estímulo amigável para a } \\
\text { continuidade de uma tarefa e a certeza de que não haverá punição ao paciente, } \\
\text { com estabelecimento de regras. Não é indulgência, é acordo. }\end{array}$ \\
\hline Verbalização de temas tabus & $\begin{array}{l}\text { Não há temas que não possam ser abordados. Todas as questões descrevem o } \\
\text { que devem descrever. Não há palavras boas ou más. Designações explícitas e } \\
\text { implícitas. }\end{array}$ \\
\hline Disposição expectante & $\begin{array}{l}\text { A segurança que o terapeuta transmite ao paciente assegura-Ihe a confiança para } \\
\text { externar o que Ihe aflige no momento propício. O paciente toma a iniciativa. } 0 \\
\text { terapeuta aguarda pacientemente. }\end{array}$ \\
\hline Audição catártica & $\begin{array}{l}\text { Implica na disposição de prestar ouvidos às inquietudes do paciente, a seus } \\
\text { melindres emocionais e a outras expressões, num esforço para compreender sem } \\
\text { interromper, guiar, aconselhar ou refutar nada que o paciente diga. A expressão } \\
\text { verbal como descarga das tensões. }\end{array}$ \\
\hline Compromisso condicional & $\begin{array}{l}\text { Compromisso alicerçado na compreensão de que o paciente deve empenhar-se, } \\
\text { gerando a condição de mutualidade interagente. Reação frente à parte saudável } \\
\text { do paciente. }\end{array}$ \\
\hline Seletividade construtiva & $\begin{array}{l}\text { Conhecer o paciente para avaliar como proceder. Decisões táticas para apontar as } \\
\text { potencialidades. }\end{array}$ \\
\hline Atitude direta não destrutiva & $\begin{array}{l}\text { Identificar a situação dominante e romper com todo o circunstancial e acessório. } \\
\text { A atitude direta como meio reorientador. }\end{array}$ \\
\hline Desempenho responsável & $\begin{array}{l}\text { Decisão consciente acerca das atitudes que restabelecem o bem-estar físico e } \\
\text { mental. O prazer da responsabilidade. }\end{array}$ \\
\hline Quando tomar as rédeas & $\begin{array}{l}\text { Nem tudo se reduz à conversação. O comportamento destrutivo ou antissocial } \\
\text { exige intervenção, ações preventivas que impõem limites e protegem o paciente. } \\
\text { Emergências. }\end{array}$ \\
\hline Linguagem do paciente & $\begin{array}{l}\text { Adoção de objetos e de alternativas que estimulem uma melhor verbalização do } \\
\text { paciente. A linguagem como estratégia. Ajuda ativa. }\end{array}$ \\
\hline Responsividade incondicion & $\begin{array}{l}\text { Respostas inequívocas que estimulam o paciente a adquirir atitudes favoráveis em } \\
\text { relação à enfermidade. A resposta substitui o afeto. }\end{array}$ \\
\hline
\end{tabular}

Fonte: Adaptado de Ruesch (1980). 
Consideramos, ainda, a visão de Kunsch ${ }^{2}$ acerca da comunicação organizacional integrada, pois é estrategicamente pensada para as práticas cotidianas de comunicação nas organizações. Kunsh ${ }^{2}$ destaca que ela deve ocorrer considerando-se três dimensões: "a humana, a instrumental e a estratégica". Interessa-nos, sobretudo a dimensão humana, que "tem de ser entendida como parte inerente à natureza das organizações, [...] pois são formadas por pessoas que se comunicam entre si e que, por meio de processos interativos, viabilizam o sistema funcional para sobrevivência e consecução de diversidades e de transações complexas”. ${ }^{.}$Kunsch $^{2}$ é categórica: "sem comunicação as organizações não existiriam".

Sob essa ótica, vislumbramos a possibilidade de articulação dos processos comunicacionais com potencial terapêutico às organizações de saúde, cuja natureza cuidadora pode propiciar um modelo de comunicação específico para organizações hospitalares.

Entender a comunicação terapêutica fortaleceu-se quando da constatação de seu desconhecimento pelos estudiosos do campo da comunicação, ou do subcampo comunicação e saúde, sendo o entendimento de domínio, em maior abrangência, da enfermagem.

Em 1993, Stefanelli³ publica um livro que define comunicação terapêutica como "uma habilidade do profissional para usar seu conhecimento sobre comunicação para ajudar a pessoa com tensão temporária a conviver com outras pessoas e a ajustar-se ao que não pode ser mudado e a superar os bloqueios à autorrealização para enfrentar seus problemas". A ênfase dessa relação, segundo a autora, se situa na comunicação interpessoal, "porque é a que mais ocorre na situação enfermeira-paciente e que facilita o desenvolvimento dos demais níveis: grupal e de massa"3.

Na medicina, a comunicação é objeto de estudos em cuidados paliativos para a comunicação de más notícias. Recentemente, os estudos da medicina narrativa vêm sendo desenvolvidos pela médica Rita Charon $^{4}$, na Universidade de Columbia, Nova York (EUA): uma prática clínica fortificada pela capacidade de sabermos o que fazer com as histórias. Não substitui nada daquilo que os clínicos fazem, mas é fortalecida pela compreensão das consequências que têm as histórias que nos são contadas. Aprendemos a habitá-las, a captar toda a evidência que essas histórias nos oferecem, a comovermo-nos com elas e a agir perante aquilo que aprendemos ${ }^{4}$.

Isso se corrobora no estágio exploratório desta pesquisa no relato, a seguir, feito pela presidente de uma Organização Não Governamental de Assistência às Famílias de Crianças Portadoras de Câncer e Hemopatias, ilustrando as inter-relações entre comunicação organizacional, medicina narrativa e comunicação terapêutica: que se podem alcançar êxitos quando se "sabe o que fazer com as histórias"4.

"A mãe, em prantos, desesperada, me disse:

- Dona Sôniai, o doutor falou que o meu filho vai morrer e ele não pode morrer. Disse para voltarmos para o Acre para que ele aproveite o resto de vida com a avó, com os brinquedos, com os amiguinhos, porque o resultado dos exames não é bom. Que não precisamos voltar mais.

[Sônia] Pela perspectiva do médico, o menino teria, no máximo, três meses de vida. Telefonei para o médico, sugerindo-lhe que alguém do hospital ligasse para a Associação no dia seguinte pedindo para a mãe voltar com o menino para uma reavaliação do exame. Que ele não desmentisse o que foi dito, mas que marcasse um retorno para o menino em data futura. Estávamos em setembro; então, que fosse marcado um retorno para dezembro, pois com o prognóstico de três meses de vida, eles acabariam não tendo como voltar. Só que eu fiquei tão abalada com o estado daquela mãe que, terminada a conversa com o médico, disse para ela que assim que ela saiu do hospital, o médico tinha visto mais alguma coisa nos exames. Pronto! No dia seguinte, ela voltou ao hospital e o médico marcou um retorno para dezembro. Na época, o menino, com 10 anos, ouvindo o médico orientar para voltarem em dezembro, disse:

- Não, doutor! Deixa eu voltar em janeiro? Porque em janeiro é o meu aniversário e gostaria de comemorar o aniversário aqui.

i O nome da presidente foi trocado a fim de se preservar a identidade. 
[Sônia] Aquilo cortou o meu coração. No dia 17 de janeiro, eu recebi um telefonema dele, dizendo que estava em Brasília para comemorar o seu aniversário. O fato é que, mesmo com toda a piora do quadro do menino enquanto estava no hospital, inexplicavelmente, esse menino não apresentou mais o tumor. Olha como esse médico poderia ter feito diferente, sem trazer tanto sofrimento para essa mãe!” (Sonia)

As 11 atitudes com potencial terapêutico de Ruesch ${ }^{1}$ foram verificadas em ambientes normais da rotina diária do hospital. Partimos do objetivo geral de verificar que atitudes poderiam ser identificadas como comunicação terapêutica no conjunto de ações estabelecido como tratamento para as crianças e o objetivo deste estudo foi o de verificar que pressupostos da comunicação terapêutica eram aplicados no tratamento das crianças e por quais categorias profissionais.

\section{Metodologia}

Os procedimentos da pesquisa qualitativa foram, em parte, definidos pela natureza da organização hospitalar, pelos critérios do Comitê de Ética em Pesquisa, e a escolha dos sujeitos foi determinada pela direção do hospital.

As estratégias metodológicas foram sendo construídas a partir da concepção de que uma instituição hospitalar tenderia a um a priori terapêutico, dada a sua natureza cuidadora; portanto, com potencial de aplicação dos processos comunicacionais terapêuticos às práticas comunicacionais nas organizações hospitalares. Desse modo, é um estudo exploratório e se caracteriza como um projeto emergente, cujo progresso se deu à medida que o contato com o local e pesquisados foi acontecendo. Isso significa, segundo Creswell5, "que o plano inicial para a pesquisa não pode ser rigidamente prescrito, e que todas as fases do processo podem mudar ou se deslocar depois que o pesquisador entrar no campo e começar a coletar os dados".

Confirmamos também, pelas premissas de Creswell $^{6}$, o entendimento de que a interpretação dos fenômenos da comunicação terapêutica e seus significados têm caráter qualitativo, pois "a pesquisa qualitativa começa com pressupostos e o uso de estruturas interpretativas/teóricas que informam o estudo dos problemas da pesquisa, abordando os significados que os indivíduos ou grupos atribuem a um problema social ou humano. Para estudar esse problema, os pesquisadores qualitativos usam uma abordagem qualitativa da investigação, a coleta de dados em um contexto natural sensível às pessoas e aos lugares em estudo, e a análise dos dados que é tanto indutiva quanto dedutiva estabelece padrões ou temas".

O estudo apontou também o esforço para se ter na equipe de Onco-Hematologia Pediátrica do hospital um comportamento comunicacional com potencial terapêutico, devido aos estudos realizados por um elemento da equipe, durante o doutorado, o qual passou a compartilhar o conhecimento adquirido, mas que não atingiu, ainda, todas as outras especialidades médicas oferecidas.

Assim, a pesquisa procura apontar os significados depreendidos sobre comunicação terapêutica, a partir da análise de conteúdo das entrevistas em profundidade, realizadas por meio de roteiro semiestruturado, a partir das 11 atitudes terapêuticas estabelecidas por Ruesch, concebidas como pré-categorias de análise, em dois grupos: o de profissionais e o de mães. Para o grupo de profissionais, foram indicados, pelo Centro Integrado e Sustentável de Ensino e Pesquisa do hospital, sete funcionários a serem entrevistados, mas somente cinco forneceram dados significativos para a pesquisa.

As três mães que compõem o segundo grupo foram indicadas por profissional de enfermagem da Unidade de Internação.

Pelo caráter qualitativo da pesquisa, utilizamos uma amostra de conveniência, obedecendo ao Conselho de Ética e aos princípios normativos do local pesquisado.

Os cinco entrevistados do grupo de profissionais são médico (1), psicólogo (1), enfermeira (2) e terapeuta (1), têm em média três anos e meio de trabalho no hospital, entre 30 e 55 anos de idade e as entrevistas 
duraram em torno de uma hora e meia. Todos leram, entenderam e assinaram o Termo de Consentimento Livre e Esclarecido. As gravações foram feitas com a concordância dos entrevistados.

As mães têm entre 30 e 45 anos de idade e formação entre Ensino Médio e Ensino Superior. Os três casos de enfermidade estão na linha do cuidado da Equipe de Onco-Hematologia-Pediátrica.

A formulação das perguntas teve por base os pressupostos da comunicação terapêutica, a partir das definições e comentários feitos por Ruesch ${ }^{1}$, e requeriam sim, não, não se aplica como resposta e espaço para o comentário que o entrevistado julgasse procedente para a verificação sob a ótica da prática dos profissionais de saúde. A resposta parcial indica que a situação apresenta a condição do sim para algum aspecto e do não para outro.

Prosseguiu-se ao esclarecimento de dúvidas todas as vezes que o entrevistado não entendeu a proposição, apresentando-se a base que a formulou, ou seja, a atitude terapêutica classificada como categoria.

As perguntas formuladas para o grupo de mães são as mesmas dirigidas ao grupo de profissionais, com o enfoque da visão da mãe/responsável do/pelo paciente e sem a relação médico-paciente como para o grupo de profissionais entrevistados.

Tomou-se o cuidado de, a todo o momento, perguntar à mãe entrevistada se desejava voltar ao quarto de internação para acompanhamento do filho em tratamento, bem como de lhe dizer que perguntasse sobre quaisquer dúvidas que as perguntas pudessem suscitar.

Com a intenção de provocar maior proximidade com a situação investigada, substituíram-se as condições impessoais das proposições pelo nome dos filhos das entrevistadas, como por exemplo: Fica claro o que preciso fazer para que o tratamento de "João" alcance bons resultados. 


\section{Resultados}

Quadro 2 - Resultados do estudo "O cotidiano terapêutico do hospital"

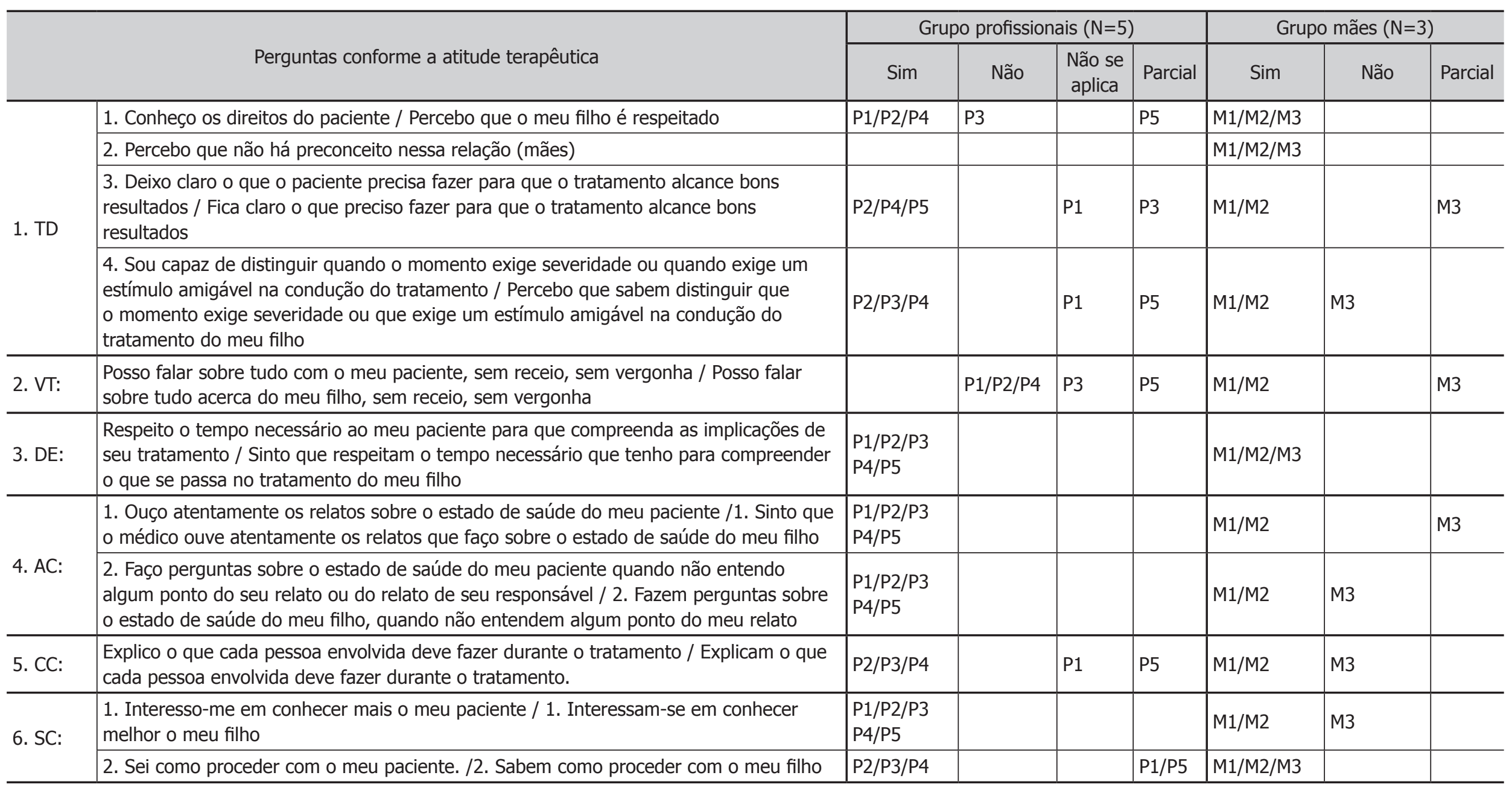

Legenda: 1.TD = Tolerância discriminada; 2. VT = Verbalização de temas tabus; 3. DE = Disposição expectante; 4. AC = Audição catártica; $\mathbf{5}$. CC = Compromisso condicional

6. $\mathbf{S C}=$ Seletividade construtiva; 7. ADNA = Atitude direta não destrutiva; $\mathbf{8}$. $\mathbf{D R}=$ Desempenho responsável; $\mathbf{9}$. TR $=$ Quando tomar as rédeas;

10. $\mathbf{L P}=$ Linguagem do paciente e 11. RI = Responsividade Incondicional. 
(Continua)

\begin{tabular}{|c|c|c|c|c|c|c|c|c|}
\hline \multirow{2}{*}{\multicolumn{2}{|c|}{ Perguntas conforme a atitude terapêutica }} & \multicolumn{4}{|c|}{ Grupo profissionais $(\mathrm{N}=5)$} & \multicolumn{3}{|c|}{ Grupo mães $(\mathrm{N}=3)$} \\
\hline & & \multirow{2}{*}{\begin{tabular}{|l} 
\\
Sim \\
$\mathrm{P} 2$
\end{tabular}} & \multirow{2}{*}{\begin{tabular}{|l}
\multicolumn{1}{|c}{ Não } \\
$\begin{array}{l}\text { P1/P3/P4 } \\
\text { P5 }\end{array}$
\end{tabular}} & $\begin{array}{l}\text { Não se } \\
\text { aplica }\end{array}$ & \multirow{2}{*}{ Parcial } & \multirow{2}{*}{\begin{tabular}{|l} 
Sim \\
$\begin{array}{l}\text { M1/M2/ } \\
\text { M3 }\end{array}$
\end{tabular}} & \multirow{2}{*}{ Não } & \multirow{2}{*}{ Parcia } \\
\hline \multirow{2}{*}{ 7. ADND: } & $\begin{array}{l}\text { 1. Posso fazer uso de palavras rudes em alguns momentos / } 1 \text {. Nunca fizeram uso de } \\
\text { palavras rudes }\end{array}$ & & & & & & & \\
\hline & $\begin{array}{l}\text { 2. Sou direto em minhas explicações, não faço rodeios / 2. São diretos em suas } \\
\text { explicações, não fazem rodeios }\end{array}$ & P3 & $\mathrm{P} 1 / \mathrm{P} 2 / \mathrm{P} 4$ & & P5 & $\begin{array}{l}\text { M1/M2/ } \\
\text { M3 }\end{array}$ & & \\
\hline 8. DR: & $\begin{array}{l}\text { Sinto que o meu modo de agir com os pacientes gera confiança / Confio totalmente em } \\
\text { quem trata do meu filho }\end{array}$ & $\begin{array}{l}\text { P1/P2/P3 } \\
\text { P4/P5 }\end{array}$ & & & & M1/M3 & & M2 \\
\hline 9. TR: & $\begin{array}{l}\text { Sei tomar as ações preventivas para o tratamento do meu paciente / Sabem tomar as } \\
\text { ações preventivas para o tratamento do meu filho }\end{array}$ & $\begin{array}{l}\mathrm{P} 1 / \mathrm{P} 2 / \mathrm{P} 3 \\
\mathrm{P} 4\end{array}$ & & & P5 & M1/M3 & M2 & \\
\hline \multirow{2}{*}{ 10. LP: } & 1. Faço-me compreender em minhas interações / 1. Compreendo tudo o que me falam & $\begin{array}{l}\mathrm{P} 1 / \mathrm{P} 2 / \mathrm{P} 3 \\
\mathrm{P} 4\end{array}$ & & & P5 & & M2/M3 & \\
\hline & $\begin{array}{l}\text { 2. Percebo quando o meu paciente ou o seu responsável não entendeu alguma } \\
\text { explicação dada / } 2 \text {. Pergunto algo que não compreendo }\end{array}$ & $\begin{array}{l}\mathrm{P} 1 / \mathrm{P} 2 / \mathrm{P} 3 \\
\mathrm{P} 4 / \mathrm{P} 5\end{array}$ & & & & $\begin{array}{l}\text { M1/M2/ } \\
\text { M3 }\end{array}$ & & \\
\hline 11. RI: & $\begin{array}{l}\text { Nunca deixo o meu paciente ou o seu responsável sem uma resposta / Nunca me } \\
\text { deixam sem uma resposta }\end{array}$ & $\mathrm{P} 1 / \mathrm{P} 2 / \mathrm{P} 5$ & P3/P4 & & & $\begin{array}{l}\text { M1/M2/ } \\
\text { M3 }\end{array}$ & & \\
\hline
\end{tabular}

Legenda: 1.TD = Tolerância discriminada; 2. VT = Verbalização de temas tabus; 3. DE = Disposição expectante; 4. AC = Audição catártica; $\mathbf{5}$. CC = Compromisso condicional

6. $\mathbf{S C}=$ Seletividade construtiva; 7. ADNA = Atitude direta não destrutiva; $\mathbf{8}$. $\mathbf{D R}=$ Desempenho responsável; $\mathbf{9}$. $\mathbf{T R}=$ Quando tomar as rédeas;

10. $\mathbf{L P}=$ Linguagem do paciente e 11. $\mathbf{R I}=$ Responsividade Incondicional.

Fonte: Os autores (2018).

Nota: Compilação dos dados aferidos nas entrevistas com profissionais $(\mathrm{N}=5)$ e mães $(\mathrm{N}=3)$. 


\section{Discussão acerca dos resultados encontrados no grupo de profissionais}

A orientação dada por Ruesch ${ }^{1}$ na atitude de tolerância discriminada é a de que é necessário respeitar um limite na relação que precisa ser estabelecida em busca de um tratamento com respeito à individualidade, estímulo amigável à continuidade de uma tarefa, ausência de preconceitos e com delimitação de acordos. Saindo da esfera da clínica psicológica e postulando que a comunicação terapêutica pode ser assumida a partir do compromisso que se estabelece para uma consciência comunicativa ${ }^{7}$ em que todos são corresponsáveis pela construção de significados na relação estabelecida, a pergunta (1.TD) 1. Conheço os direitos do paciente, apontou que, dos cinco entrevistados, três profissionais têm clareza nesse sentido. A resposta parcial de $\mathrm{P}_{5}$ refere-se ao fato de que conhece somente os obrigatórios, mas afirma a necessidade de se aprofundar.

Compreendemos os direitos do paciente como sendo aqueles relacionados às questões deontológicas esperadas pelos profissionais que lhes oferecem tratamento.

O Sistema Único de Saúde (SUS) ${ }^{8}$ publicou, em 2006, a Carta dos Direitos dos Usuários da Saúde "o documento, que tem como base seis princípios básicos de cidadania, caracteriza-se como uma importante ferramenta para que o cidadão conheça seus direitos e deveres no momento de procurar atendimento de saúde, tanto público como privado. [...] Foi elaborado de acordo com seis princípios basilares que, juntos, asseguram ao cidadão o direito básico ao ingresso digno nos sistemas de saúde, sejam eles públicos ou privados: 1. Todo cidadão tem direito ao acesso ordenado e organizado aos sistemas de saúde. 2. Todo cidadão tem direito a tratamento adequado e efetivo para seu problema. 3. Todo cidadão tem direito ao atendimento humanizado, acolhedor e livre de qualquer discriminação. 4. Todo cidadão tem direito a atendimento que respeite a sua pessoa, seus valores e seus direitos. 5. Todo cidadão também tem responsabilidades para que seu tratamento aconteça da forma adequada. 6. Todo cidadão tem direito ao comprometimento dos gestores da saúde para que os princípios anteriores sejam cumpridos”.

Mas o conteúdo da Carta ainda é desconhecido pelos profissionais de saúde e os direitos declarados também não são amplamente assegurados. Esses questionamentos obrigariam a uma discussão que foge à proposta deste estudo, mas revela o desconforto das dissonâncias provocadas pela insustentabilidade das condições de saúde no país: malversação do erário, sucateamento dos hospitais públicos e abuso na administração dos planos privados de saúde.

Como a realidade estudada difere bastante das outras de que se têm notícias, retoma-se, aqui, o foco para o hospital pesquisado, considerando que, nesse universo, três entrevistados afirmam conhecer os direitos dos pacientes, um afirma não conhecer, e o outro conhece parcialmente.

Ainda na atitude tolerância discriminada (1.TD), em relação à proposição 3. Deixo claro o que o paciente precisa fazer para que o tratamento alcance resultados percebe-se que um profissional (P1) se posiciona parcialmente frente à questão, pois menciona que entende que sua relação com o prontuário é uma área em que ele começa a se adaptar, dada a atividade que exerce no contexto do cuidado.

A proposição 4, inerente ainda à atitude de tolerância discriminada (1. TD), revela que somente um profissional identifica parcialmente a habilidade.

No tocante à verbalização de temas tabus (2. VT), três profissionais apresentam dificuldades para falar sobre qualquer coisa com os seus pacientes. O entrevistado $\mathrm{P}_{3}$ indica que, nessa condição:

"Uso o bom senso e entendo que há no hospital os profissionais certos para lidar com o que não alcanço" (Entrevistado $\left.P_{3}\right)$. 
Na disposição expectante (3. DE), $\mathrm{P} 4$ aponta uma parcialidade para a questão, dizendo que

"A gente respeita o tempo de aceitação, mas o tratamento tem de ser feito, é imediato. Não posso dar um tempo para o paciente entender o que é um tratamento, senão ele morre" (Entrevistado P4).

Em compromisso condicional (5. CC), $\mathrm{P}_{5}$ argumenta que o fato de a equipe de Onco-hematologia Pediátrica atuar de forma multidisciplinar, favorece a interação de todos na questão. Sua postura parcial se dá quando distingue a possibilidade de algo não ser compreendido pela equipe ou de alguma informação não ser devidamente elucidada ao paciente.

Em seletividade construtiva (6. SC), na proposição 2, Sei como proceder com o meu paciente, dois profissionais posicionam-se parcialmente ante a questão, pois entendem que, em algumas circunstâncias, precisam da ajuda de outras pessoas da equipe.

Em atitude direta não destrutiva (7. ADND), um profissional afirma que pode fazer sim o uso de palavras rudes (proposição 1) e os demais afirmam que não.

Ruesch $^{1}$ não orienta ser rude. Ele orienta que: "com este tipo de paciente, o terapeuta deve ser direto. Tem que deixar de lado qualquer acessório, delicadeza, racionalização e ressentimento. Deverá usar palavras que provoquem o impacto adequado no estado emocional do paciente". Ainda em (7. ADND), P4 parece mostrar uma incoerência na proposição 2.

"Sou direto em minhas explicações, não faço rodeios", porque na atitude direta não destrutiva" (Entrevistado P4).

Ela afirma:

"A gente respeita o tempo de aceitação, mas o tratamento tem de ser feito, é imediato" (Entrevistado P4).

Porém, na disposição expectante, sua resposta é:

"Não posso dar um tempo para o paciente entender o que é um tratamento, senão ele morre" (Entrevistado P4).

Para a compreensão da linguagem do paciente (10. LP), P5 apontou que sua dificuldade está entre os colegas de trabalho, mas que se faz entender com os pacientes.

E, finalmente, na atitude de responsividade incondicional (11. RI), dois profissionais se posicionam com a resposta não, mas no que se refere ao caráter da atitude de desempenho responsável $\mathrm{P}_{3}$ afirma:

"Nem que seja para dizer: eu não sei” (Entrevistado P3).

E P4:

“Não tenho resposta para tudo" (Entrevistado P4).

\section{Discussão acerca dos resultados encontrados no grupo de mães}

No que se refere à tolerância discriminada (1.TD), a proposição 2. Percebo que não há preconceito nessa relação, direcionada somente às mães, busca aferir não só a tolerância discriminada inerente à atitude, mas abarca também tanto a Política Nacional de Humanização (PNH) quanto as diretrizes gerais para implementação da PNH nos diferentes níveis de atenção:

"sensibilizar as equipes de saúde em relação ao problema da violência intrafamiliar (criança, mulher e idoso) e quanto à questão dos preconceitos (sexual, racial, religioso e outros) na hora da recepção e dos encaminhamentos". 
Ainda em (1.TD), na proposição 3, Fica claro o que preciso fazer para que o tratamento alcance bons resultados, M3 esbarra na dificuldade de entender o que se passa com a filha:

"Mais ou menos. A gente pergunta: "Doutor, o que é exatamente o osteosarcoma"? Ele não esclarece o que é exatamente. Só fala assim: "Vamos fazer o tratamento, começar com a quimioterapia, depois a cirurgia, aí vão surgindo os resultados”, mas esclarecer assim, exatamente, o que é mesmo ele não esclareceu” (Entrevistada M3).

Já na proposição 4 de (1.TD), Percebo que sabem distinguir que o momento exige severidade ou que exige um estímulo amigável na condução do tratamento do meu filho, M3 apresenta um desconforto com a forma pela qual o médico verbaliza a situação:

"Não, ele é mais severo. Joga com a realidade mesmo, porque às vezes a gente quer ouvir uma coisa, mas eles tocam mesmo no ponto da doença que está acontecendo (Entrevistada M3).

Em verbalização de temas tabus (2. VT), M3 aponta que percebe que a equipe de oncologia se mostra mais preparada para lidar com a situação, mas que o ortopedista que atende à filha, não.

"Eu diria que com o ortopedista, não. Com a oncologista, sim. Ela já é mais de conversar, explicar as coisas, mas o ortopedista não [...]. Ele não é de falar. Ele é de escrever e falar para a gente fazer as coisas e pronto. A oncologista, não, é de pouca escrita e de mais conversa. Ela senta com a gente, esclarece, pergunta se a gente tem alguma dúvida, essa é a diferença” (Entrevistada M3).

Na proposição 1 da atitude de audição catártica (4.AC): Sinto que o médico ouve atentamente os relatos que faço sobre o estado de saúde do meu filho, M3 apresenta uma certa compreensão em relação ao reivindicado por ela nas atitudes de tolerância discriminada e de verbalização de temas tabus:

"O ortopedista não. A oncologista, sim. Eu acho que é porque ele é só ortopedista. No caso dele, é mais a cirurgia, então, como a doença dela é tratada mais com oncologista, eu até entendo o lado dele, porque é assim, fica mais na parte de ver os resultados do exame e na parte da cirurgia. E ela [a oncologista] já é mais na base da conversa" (Entrevistada M3).

A diferença de postura do médico ortopedista em relação à da oncologista parece ficar mais patente quando M3 responde à proposição Faz perguntas sobre o estado de saúde do meu filho quando não entende algum ponto do meu relato (4.AC). Com sibilância, ela também verbaliza que o ortopedista não faz perguntas, mas que a oncologista sim.

A resposta de M3 para a questão Explicam o que cada pessoa envolvida deve fazer durante o tratamento, formulada sobre a atitude compromisso condicional (5.CC), parece revelar uma incoerência em relação aos argumentos anteriores, pois afirma que nenhum dos dois médicos explica o que cada pessoa envolvida deve fazer durante o tratamento.

Em seletividade construtiva (6.SC), M3 identifica apenas o cumprimento da anamnese protocolar de início de atendimento:

"Não, não teve, foi só sobre a doença, não sobre ela. Porque eles fizeram tipo uma biografia dela, desde que começou a doença até agora, mas só sobre a doença, de como a gente chegou aqui, de como aconteceu. Só sobre isso aí” (Entrevistada M3). 
Em desempenho responsável (8. DR), M2 se manifesta em relação a técnicos e enfermeiros:

"Mais ou menos. Têm uns que chegam novos aqui, que estão em treinamento, e a gente confia nos mais antigos. Nos mais novos, eu já peguei erro de colocar uma coisa de um paciente para outro; se a gente não estiver atenta, né? Eu falei: olha esse remédio não é dele não! Mas eu acho que é por causa de treinamento mesmo" (Entrevistada M2).

Em relação à proposição Sabem tomar as ações preventivas para o tratamento do meu filho, relativa à atitude tomar as rédeas (9.TR), M2 aponta que os enfermeiros ficam na dependência dos médicos:

"Enfermeiro não faz isso não. Eles ficam dependendo totalmente do médico" (Entrevistada M2).

No que se refere à proposição Compreendo tudo o que me falam, da atitude de compreensão da linguagem do paciente (10. LP), M2 e M3 apontam um dado significativo relativo a enfermeiros/ técnicos e médicos, respectivamente:

"Nem sempre. Quando eles têm muitas crianças, às vezes, não dão conta. Uma vez, o meu filho ficou 40 minutos com o cateter sem medicamento, porque eles estavam muito ocupados com as outras crianças. Briguei com eles, porque eles mesmos me orientaram a não deixar sem soro na veia depois que acaba o medicamento, porque senão entope o cateter e é mais uma cirurgia de retirada e recolocação em outro lugar. Não compreendi porque eles me orientaram a pedir que lhes avisasse sobre ofato, se não atenderam conforme eles orientaram. A enfermeira chefe me deu razão, mas a técnica não gostou de eu ter brigado. Me chamou de estressada" (Entrevistada M2).

"Nem sempre. Às vezes, tenho que fazer a mesma pergunta duas ou três vezes para eu entender" (Entrevistada M3).

Contudo, de uma maneira geral, os relatos livres revelaram satisfação com o atendimento recebido:

"Olha, eu sou fã deste hospital. Eu acho que é importante a forma humana dos funcionários, a forma como eles interagem. Os enfermeiros, quando vão trocar de turno, passam de salinha em salinha para informar como cada paciente está, falam sobre o remédio, falam se a criança está triste, se a mãe saiu, se o pai ficou, para que a enfermeira do próximo turno saiba como está deixando o paciente. A gente não é só um número aqui" (Entrevistada M2).

"Aqui, sofrimento não tem. Se todo hospital usasse este como exemplo, a saúde pública seria totalmente diferente, porque desde a entrada até a internação, tudo aqui dentro, os profissionais, tudo é excelente. Desde os seguranças, lá na portaria, os vigilantes. Este hospital aqui é excelente, excelente. Eu dou graças a Deus de a minha filha ter entrado aqui dentro, porque foi ótimo, excelente" (Entrevistada M3).

\section{Comunicação integrando a organização hospitalar e seu potencial terapêutico: indicações para um diálogo}

Uma comunicação organizacional integrada demanda a internalização, por todos, da incumbência de uma comunicação que se faça terapêutica, em todos os níveis de interação e em qualquer circunstância, não se restringindo às ações clínico-hospitalares. 
Marchiori ${ }^{10}$ advoga "ao pensarmos nas organizações de hoje, surge naturalmente a preocupação com a gestão estratégica da comunicação [...]. Significa orientar, criar e cultivar relacionamentos, por meio da interação social [...]. A nova exigência é olhar para além das estruturas, tendo o foco na análise dos processos. Neste sentido, considerar o contexto de cada organização é uma postura fundamental. Trabalhar sua dimensão comunicativa é oportunizar o desenvolvimento e a sustentabilidade das organizações".

Este estudo verificou que os procedimentos e rotinas não dependem apenas das estruturas, mas ainda exige um planejamento que possa oficializar políticas de comunicação que estabeleçam uma consciência comunicativa apoiadas nas premissas da comunicação terapêutica.

Quanto aos fluxos comunicacionais, observou-se uma falha na comunicação entre equipes: relatou-se o caso em que uma criança estava internada para procedimentos de quimioterapia e a central de consultas ligou para a sua mãe a fim de saber o motivo pelo qual sua filha não comparecera à consulta médica. Em outro caso, uma médica prescreveu a internação para uma criança e a equipe de recepção da internação alegou leito insuficiente, mas teve de voltar atrás porque a médica sabia da existência do leito para a criança ser internada.

Kunsch $^{11}$ aponta a dificuldade de se conseguir estabelecer uma linearidade nesses fluxos que se estabelecem nas intrincadas redes relacionais da organização: “[...]. Trata-se de uma rede relacional entre indivíduos, departamentos, unidades e organizações. Se analisarmos comunicações existentes, que atuam em distintos contextos sociais". No mesmo estudo, ela afirma que “[...]. Vale também acrescentar que não é pelo fato de existir uma comunicação formalizada ou sistematizada que todos os problemas de uma organização estão ou serão resolvidos"11.

Infere-se ainda, que os relatos apresentados por M3 acerca do modo distante de atendimento do ortopedista em relação ao da oncologista, longe se serem negligenciados, precisam considerar o dado temporal de tratamento, que pode ter influenciado a dificuldade de interação com o ortopedista. A filha estava em tratamento havia apenas um mês; o de M1 havia cinco meses e, no caso de M2, houve uma recidiva depois de dois anos e meio de tratamento no hospital pesquisado.

\section{Considerações finais}

Verificamos, de início, que no hospital pesquisado os pacientes são conhecidos pelo nome, pela condição que lhes afeta, mas, sobretudo, pela filosofia de cultivo de relacionamento duradouro entre os que lá conseguem tratamento. É dada atenção cuidadosa às crianças para que aprendam a conviver com suas doenças crônicas, mas não se transformem em enfermos com doenças agudas.

O recorte empírico apresentado neste artigo tem a perspectiva de entender quando a comunicação se revela com potencial terapêutico. Para isso, visando à verificação de como se processa a relação comunicacional hospital-paciente-hospital, os profissionais envolvidos foram abordados com base em questões formuladas a partir das interpretações feitas, pelas autoras, sobre os comportamentos esperados em cada atitude terapêutica, de acordo com a teoria desenvolvida por Jürgen Ruesch ${ }^{1}$.

Os dados obtidos indicam que os pressupostos da comunicação terapêutica são aplicados no tratamento das crianças da unidade de Onco-Hematologia Pediátrica do hospital onde foi feita a pesquisa, ainda que sem o conhecimento consciente de sua prática.

Do ponto de vista do paciente, representado legalmente pela mãe, houve indicação das possíveis vicissitudes inerentes às relações humanas, mas, para além do sim ou do não como resposta, houve reconhecimento da excelência do hospital, bem como do esforço empreendido para um comportamento comunicacional consciente.

Como limitações deste estudo, entendemos que os resultados apresentados são inerentes às condições únicas do locus pesquisado - um hospital público terciário do Distrito Federal, cujas especialidades ali tratadas são aquelas de maior complexidade, exigindo instalações, pessoal e tecnologia em conformidade 
com a função a que se destina - e não representam, consequentemente, as realidades múltiplas encontradas em muitos hospitais do Brasil.

Tal multiplicidade possibilita que outros estudos sejam desenvolvidos. Desse modo, propomos novas investigações que permitam explorar perspectivas de interface e aplicação da teoria de Ruesch ${ }^{1}$ à comunicação organizacional integrada.

\section{Referências}

1. Ruesch J. Comunicación terapéutica: psiquiatria, psicopatologia y psicosomatica. Buenos Aires: Editorial Paidós; 1980.

2. Kunsch MMK. Comunicação organizacional: conceitos e dimensões dos estudos e das práticas. In: Marchiori M, organizadora. Faces da cultura e da comunicação organizacional. 2 ed. São Caetano do Sul: Difusão Editora; 2008:167-90.

3. Stefanelli MC. Comunicação com o paciente: teoria e ensino. São Paulo: Robe; 1993.

4. Charon R. Medicina narrativa. Entrevista. Jornal Notícias Médicas. N. 3089, de 29.9.2010. [citado 06 jun. 2018]. Disponível em: http://www.ulices.org/images/documentos/narrativamedicina2010.pdf

5. Creswell JW. Projeto de pesquisa. Métodos qualitativo, quantitativo e misto. 3 ed. Porto Alegre: Artmed; 2010.

6. Creswell JW. Investigação qualitativa e projeto de pesquisa. 3 ed. Porto Alegre: Artmed; 2014.

7. Duarte J, Monteiro G. Potencializando a comunicação nas organizações. In: Kunsch MMK. Comunicação organizacional: linguagem, gestão e perspectivas. Vol. 2. São Paulo: Saraiva; 2009:333-59.

8. Ministério da Saúde (BR). Carta dos direitos dos usuários da saúde: ilustrada. 2 ed. Brasília; 2007.

9. Ministério da Saúde (BR). Secretaria-Executiva. Núcleo Técnico da Política Nacional de Humanização. Humaniza SUS. Política Nacional de Humanização: a humanização como eixo norteador das práticas de atenção e gestão em todas as instâncias do SUS. Brasília; 2004.

10. Marchiori M. Cultura e comunicação organizacional: uma perspectiva abrangente e inovadora na proposta de inter-relacionamento organizacional. In: Marchiori Marlene, organizadora. Faces da cultura e da comunicação organizacional. 2 ed. São Caetano do Sul: Difusão Editora; 2008. p. 28.

11. Kunsch MMK. Planejamento de relações públicas na comunicação integrada. 5 ed. São Paulo: Summus; 2003. 